\title{
Correction to: Measurement of entropy and quantum coherence properties of two type-I entangled photonic qubits
}

\author{
Ali Motazedifard ${ }^{1,2,3}$ (D) Seyed Ahmad Madani ${ }^{1,2} \cdot$ N. S. Vayaghan ${ }^{1,2}$ \\ Published online: 16 November 2021 \\ ๑) Springer Science+Business Media, LLC, part of Springer Nature 2021
}

\section{Correction to: Optical and Quantum Electronics (2021) 53:378 https://doi.org/10.1007/s11082-021-03067-8}

The article "Measurement of entropy and quantum coherence properties of two type-I entangled photonic qubits", written by Ali Motazedifard, Seyed Ahmad Madani and N. S. Vayaghan, was originally published online on 3 July 2021 with Open Access under a Creative Commons Attribution 4.0 International License.

After publication in volume 53, issue 7, page 1-26 the author(s) decided to cancel the Open Access. Therefore, the copyright of the article has been changed on 2 November 2021 to (C) Springer Science + Business Media, LLC, part of Springer Nature 2021 with all rights reserved.

Publisher's Note Springer Nature remains neutral with regard to jurisdictional claims in published maps and institutional affiliations.

The original article can be found online at https://doi.org/10.1007/s11082-021-03067-8.

Ali Motazedifard

motazedifard.ali@gmail.com

1 Quantum Optics Group, Iranian Center for Quantum Technologies (ICQTs), Tehran, Iran

2 Quantum Communication Group, Iranian Center for Quantum Technologies (ICQTs), Tehran, Iran

3 Quantum Sensing and Metrology Group, Iranian Center for Quantum Technologies (ICQTs), Tehran, Iran 